Terbit online pada laman web jurnal : http://e-journal.sastra-unes.com/index.php/JIPS

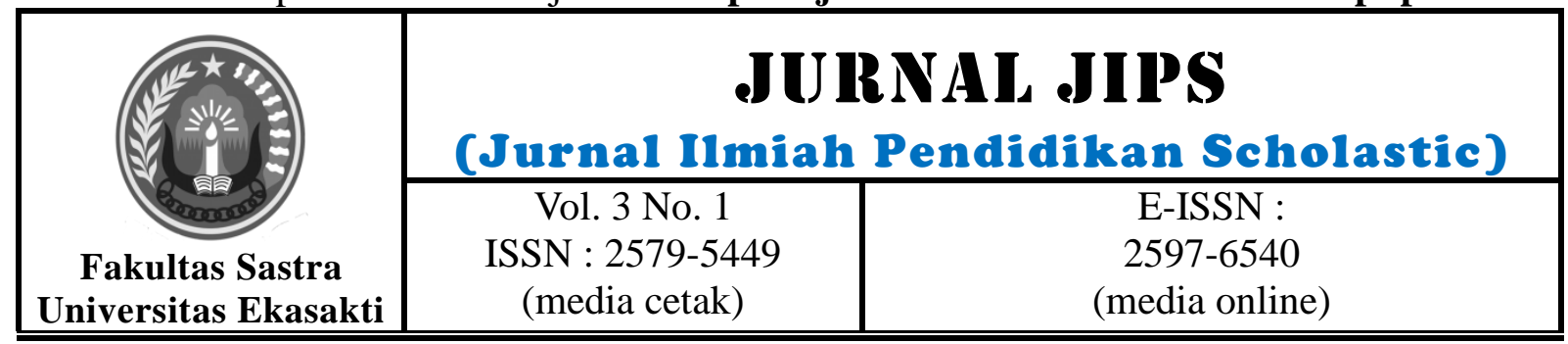

IMPLEMENTATION OF POLICY PRESIDENTIAL REGULATION NUMBER 22 OF YEARS 2009 IN EMPOWERING COMMUNITIES TO IMPLEMENT THE PERFORM HOME AREA OF FOOD

\author{
Reflinda \\ STIA Adabiah Padang \\ reflindasyafwardi65@gmail.com
}

\begin{abstract}
Perpres's policy implementation Number 22 Years 2009 Deep Empower Societies to Perform Home Area Programs angan Abidinging to constitute one of efforts to give knowledges and sciences to Wanita Tani Arai's Pinang agglomerate members that Abiding Areca more reduce dependency to rice commodity. Yard commodity pickings as commodity umbian as cassava. Parsnip creeps, corn, sukun's banana and commodity can be made as flour that can at o as victuals interesting and nutritive at a swoop gets to be utilized for wheat substitution that on eventually dependable society to import commodity as wheat gets to be reduced.
\end{abstract}

Keywords: Society, Home, Community

(C) 2019Jurnal JIPS

\title{
IMPLEMENTASI KEBIJAKAN PERPRES NOMOR 22 TAHUN 2009 DALAM MEMBERDAYAKAN MASYARAKAT UNTUK MELAKSANAKAN PROGRAM KAWASAN RUMAH PANGAN LESTARI
}

\begin{abstract}
Abstrak
Implementasi kebijakan Perpres Nomor 22 Tahun 2009 Masyarakat Pemberdayaan Dalam untuk Melakukan Program Area Rumah angan Bertahan merupakan salah satu upaya untuk memberikan pengetahuan dan ilmu pengetahuan kepada anggota aglomerat Pinang Wanita Tani Arai bahwa Abiding Areca lebih mengurangi ketergantungan pada komoditas beras. Pekarangan komoditas sebagai komoditas umbian seperti singkong. Parsnip creeps, jagung, pisang sukun dan komoditas dapat dibuat sebagai tepung yang pada umumnya menarik dan bergizi sekaligus dapat digunakan untuk substitusi gandum yang pada akhirnya masyarakat yang dapat diandalkan untuk mengimpor komoditas karena gandum dapat dikurangi.
\end{abstract}

Keywords: Masyarakat, Rumah, Komunitas

doi.org/10.5281/zenodo.3364312

Jurnal JIPS (Jurnal Ilmiah Pendidikan Scholastic) Vol. 3 No. 1 (2019) ISSN : 2579-5449

This work is licensed under a Creative Commons Attribution-NonCommercial 4.0 International License. 


\section{INTRODUCTION}

Pembukaan Undang-undang Dasar Negara Republik Indonesia 1945 menjelaskan bahwa meningkatkan kesejahteraan masyarakat dan mencerdaskan kehidupan bangsa merupakan hal yang sangat penting dalam melaksanakan pembangunan saat ini.Keberhasilan pembangunan nasional suatu bangsa ditentukan oleh keberhasilan sumberdaya manusia (SDM) yang berkualitas, yaitu memiliki fisik yang tangguh, mental yang kuat, kesehatan yang prima, serta otak yang cerdas.Hal ini sangat ditentukan oleh asupan gizi yang baik dalam hal kualitas maupun kuantitas.Salah satu upaya yang dapat dilakukan adalah melaksanakan penganekaragaman pangan menuju konsumsi pangan yang aman, beragam, bergizi seimbang. Penganekaragaman pangan akan mempunyai nilai manfaat yang besar apabila mampu menggali, mengembangkan dan mengoptimalkan pemanfaatan sumber pangan lokal.

Pangan adalah kebutuhan yang paling esensial untuk menjalani kehidupan ini. Kelangkaan BBM di tingkat dunia telah memicu terjadinya krisis pangan global dikarenakan penggunaan hasil pangan untuk membuat energi nabati yang dampaknya adalah penurunan ketersediaan pangan sehingga berpotensi menambah jutaan masyarakat rawan pangan. Kondisi ini merupakan suatu ancaman bagi kelanjutan hidup jutaan manusia didunia terutama yang mempunyai keterbatasan akses terhadap pangan sehingga hal ini perlu diantisipasi dengan seksama. Dimasa mendatang, upaya pemenuhan pangan akan menghadapi tantangan yang semakin berat. Isu dampak perubahan iklim yang akhir-akhir ini menjadi pembicaraan dan perhatian dunia intenasional membuktikan bahwa iklim sangat berpengaruh besar terhadap keberlanjutan kehidupan manusia. Di sisi lain yang tidak kalah pentingnya adalah pertumbuhan penduduk selalu diiringi oleh meningkatnya kebutuhan hidup, sementara ketersediaan lahan dan air tidak berkembang, fenomena ini menyebabkan tekanan terhadap kedua sumberdaya ini semakin berat.

\section{RESEARCH METHODS}

Penelitian ini dilakukan dengan menggunakan jenis penelitian diskriptif kualitatif, yaitu penelitian yang menggambarkan dan menganalisa untuk memecahkan masalah yang ada. (Sudjana, 2001:193)

\section{LokasiPenelitian}

Penelitian ini dilaksanakan di Kelompok Wanita Arai Pinang Lestari Desa Talawi Hilir Kecamatan Talawi Kota Sawahlunto.

Tabel. 1

DaftarInformanPenelitian

\begin{tabular}{|c|l|c|}
\hline No & \multicolumn{1}{|c|}{ Informan } & Jumlah \\
\hline 1. & KetuaKelompokWanita Arai Pinang Lestari & 1 Orang \\
\hline 2. & SekretarisKelompok & 1 Orang \\
\hline 3. & BendaharaKelompok & 1 Orang \\
\hline 4. & AnggotaKelompok & 3 Orang \\
\hline 5. & Kepala Badan Ketahanan Pangan Sumbar & 1 Orang \\
\hline 6. & Kepala BidangPenganeka ragaman Konsumsi & 1 Orang \\
\hline
\end{tabular}

doi.org/10.5281/zenodo.3364312

Jurnal JIPS (Jurnal Ilmiah Pendidikan Scholastic) Vol. 3 No. 1 (2019) ISSN : 2579-5449

This work is licensed under a Creative Commons Attribution-NonCommercial 4.0 International License. 
Reflinda

Jurnal JIPS (Jurnal Ilmiah Pendidikan Scholastic) Vol. 3 No. 1 (2019) ISSN : 2579-5449

\begin{tabular}{|c|l|c|}
\hline & Pangan Badan Ketahanan Pangan Sumbar & \\
\hline 7. & Kabid Ketahanan Pangan Kota Sawahlunto & 1 Orang \\
\hline 8. & Kepala Desa Talawi Hilir Kecamatan Talawi & 1 Orang \\
\hline Jumlah Keseluruhan & 10 Orang \\
\hline
\end{tabular}

\section{RESEARCH FINDING}

Implementasi Kebijakan Perpres Nomor 22 Tahun 2009 Dalam Memberdayakan Masyarakat Untuk Melaksanakan Program Kawasan Rumah Pangan Lestari.

Implementasi Kebijakan Perpres Nomor 22 Tahun 2009 dalam memberdayakan masyarakat untuk melaksanakan Program Kawasan Rumah Pangan Lestari dilaksanakan dalam bentuk optimalisasi pemanfaatan pekarangan yang dilaksanakan oleh seluruh anggota kelompok wanita tani arai pinang lestari di Desa Talawi Hilir Kecamatan Talawi Kota Sawahlunto. Upaya optimalisasi pemanfaatan pekarangan dilakukan oleh setiap anggota kelompok dengan cara menanam tanaman komoditi pangan berupa tanaman sayur-sayuran, buah-buahan, umbi-umbian bahkan usaha ternak. Pengembangan komoditi usaha pekarangan anggota kelompok juga beranekaragam dengan berbagai jenis komoditi dengan mengoptimalkan lahan pekarangannya seperti :

1. Sumber karbohidrat berupa ubi kayu, ubi jalar, jagung dan talas

2. Sumber Sayuran berupa bayam, kangkung, kacang panjang, buncis, cabe merah, cabe rawit, pitulo, gambas, terung hijau dan terung ungu.

3. Sumber buah-buahan berupa rambutan, pisang, manga, sawo, sirsak, papaya dan naga.

4. Sumber tanaman toga berupa kunyit, jahe, laos, sitawa, sidingin, sikumpai, sirih merah, sirih hijau dll.

5. Sumber peternakan berupa ayam dan itik

6. Sumber perikanan berupa ikan patin, lele, mas rayo, nila dan gurame
Kegiatan optimalisasi pemanfaatan pekarangan dengan berbagai jenis macam tanaman yang diusahakan oleh masing-masing anggota Kelompok Wanita Arai Pinang Lestari sangat bermanfaat sekali bagi anggota. Selama ini anggota kelompok selalu membeli sayur-sayuran di pasar untuk kebutuhan anggota keluarganya, sekarang tidak lagi ke pasar mencari sayur melainkan sudah dapat dipetik langsung panganpangan segar di halaman rumah anggota masingmasing sebagai sajian dalam menu keluarga setiap hari yang dapat langsung mereka konsumsi, bahkan beberapa anggota juga telah dapat menjual sayur-sayuran hasil pekarangannya ke pasar yang dapat dijadikan sebagai penambah ekonomi keluarga atau sumber pendapatan keluarga. sangatlah jelas bahwa masyarakat desa talawi hilir mengalami banyak kemajuan dan perubahan pola konsumsi kearah yang lebih baik dalam rangka perbaikan pola konsumsi anggota keluarga mereka. Karena hasil dari pekarangan mereka yang akan dikonsumsi oleh anggota keluarga berupa pangan-pangan segar yang bebas dari segala macam pestisida dan bahan-bahan kimia lainnya yang dapat merusak kesehatan anggota keluarga mereka nantinya. Jadi jelaslah Program Kawasan Rumah Pangan Lestari ini sangat berdampak positif sekali bagi kemajuan dan perkembangan Desa Talawi Hilir.Salah satunya adalah berkurangnya jumlah rumah tangga miskin yang ada di Desa Talawi Hilir Kecamatan Talawi Kota Sawahlunto. Hal ini dapat dilihat dari Data BPS Tahun 2013 sebagai berikut : 
Reflinda

Jurnal JIPS (Jurnal Ilmiah Pendidikan Scholastic) Vol. 3 No. 1 (2019) ISSN : 2579-5449

Tabel 1

\begin{tabular}{|c|l|c|c|c|c|}
\hline No. & Nama Kelurahan & $\begin{array}{c}\text { Jumlah } \\
\text { Penduduk }\end{array}$ & $\begin{array}{c}\text { Jumlah } \\
\text { KK }\end{array}$ & $\begin{array}{c}\text { Jumlah } \\
\text { Gakin }\end{array}$ & $\begin{array}{c}\text { Jumlah } \\
\text { Gakin } \\
(\%)\end{array}$ \\
\hline 1. & Sikalang & 1.410 & 513 & 27 & 5,65 \\
\hline 2. & Rantih & 594 & 173 & 6 & 3,46 \\
\hline 3. & Salak & 1.335 & 361 & 19 & 5,81 \\
\hline 4. & Sijantang Koto & 1.261 & 332 & 17 & 5,12 \\
\hline 5. & Talawi Hilir & 4.050 & 1.091 & 32 & 3,94 \\
\hline 6. & Talawi Mudik & 2.732 & 856 & 22 & 3,73 \\
\hline 7. & Bukit Gadang & 1.267 & 386 & 18 & 4,66 \\
\hline 8. & Batu Tanjung & 1.902 & 551 & 26 & 5,08 \\
\hline 9. & Kumbayau & 1.546 & 475 & 25 & 6,73 \\
\hline 10. & Datar Mansiang & 164 & 47 & 15 & 31,91 \\
\hline 11. & Tumpuk Tangah & 1.882 & 612 & 26 & 4,73 \\
\hline
\end{tabular}

Dari tabel diatas dapat terlihat kemajuan Desa Talawi Hilir yakni dari jumlah penduduk yang paling banyak yaitu berjumlah 4.050 jiwa, jumlah KK 1.091 memiliki keluarga miskin sebanyak 32 KK dengan persentase sebesar $3,94 \%$. Jadi dalam melaksanakan suatu kebijakan, peranan pemerintah dan tokoh masyarakat sebagai elit di suatu wilayah atau nagari sangatlah penting untuk menentukan keberhasilan sebuah program yang telah dikeluarkan pemerintah,agar anggota-anggota kelompok yang melaksanakan program dimaksud lebih bersemangat dan berpartisipasi aktif sehingga program yang dilaksanakan lebih berkembang dan berjalan dengan baik sesuai dengan harapan organisasi. Sehingga jelaslah peranan elit dan pemerintah sangat menentukan untuk keberhasilan suatu program disuatu wilayah. Selain itu model implementasi kebijakan dipengaruhi oleh beberapa variabel yang saling berkaitan. Variabel-variabel tersebut apabila dikaitkan dengan Implementasi Perpres Nomor 22 Tahun 2009 Dalam Memberdayakan Masyarakat untuk melaksanakan Program Kawasan Rumah Pangan Lestari adalah sebagai berikut :

a. Standar, sasaran dan tujuan kebijakan yaitu adanya organisasi kelompok wanita tani arai pinang lestari yang melaksanakan program Kawasan Rumah Pangan Lestari dengan sasaran dan tujuan dapat memanfaatkan potensi sumberdaya lokal melalui optimalisasi pemanfaatan pekarangan.

b. Sumber daya yaitu melalui Dinas Instansi terkait dalam bentuk penyaluran dana bansos ke rekening anggota kelompok sekaligus memberikan sosialisasi dan penyuluhan terhadap pelaksanaan program yang diberikan.

c. Karakteristik organisasi pelaksana yaitu anggota kelompok wanita tani arai pinang lestari menerima untuk melaksanakan program yang diberikan.

d. Sikap para pelaksana yaitu setiap anggota melaksanakan program melalui pemanfaatan lahan pekarangannya dengan menanam berbagai jenis komoditi pangan yang dapat dikonsumsi anggota keluarga.

e. Komunikasi antar organisasi terkait dan kegiatan-kegiatan pelaksanaan yaitu adanya penyuluhan-penyuluhan dari PPL dan Dinas Instansi terkait kepada pengurus dan anggota kelompok dalam melaksanakan program agar program yang diberikan berhasil dengan baik.

f. Lingkungan sosial, ekonomi dan politik yaitu lingkungan sosial masyarakat desa Talawi Hilir sangat mendukung terhadap pelaksanaan program ini karena daerahnya yang subur ditambah dengan mata pencaharian masyarakat Desa Talawi Hilir yang pada umumnya bergerak pada sektor pertanian sehingga dengan adanya program ini sangat mendukung sekali untuk kemajuan masyarakatnya.

Berkembangnya pelaksanaan Program Kawasan Rumah Pangan Lestari di Kelompok Wanita Tani Arai Pinang Lestari di Desa Talawi Hilir karena adanya pengembangan kemitraan kelompok yang tumbuh dan berkembang secara sinergis yang didukung oleh hal-hal sebagai berikut : 
a. Suasana keterbukaan, kekeluargaan, kebersamaan anggota kelompok

b. Kerjasama dan adanya hubungan yang harmonis dengan pemerintah desa sehingga mendapat dukungan dalam setiap kegiatan kelompok

c. Kerjasama dan hubungan erat dengan penyuluh pertanian, UPTD BPP dan Dinas Pertanian dan Kehutanan Kota Sawahlunto sehingga Program yang direncanakan dapat dilaksanakan dengan baik.

d. Kerjasama dengan perangkat desa Talawi Hilir, PKK Kecamatan Talawi terhadap pemberdayaan perempuan dalam keluarga dan peran serta KWT Arai Pinang dalam menghadapi berbagai perlombaan Tingkat Desa Talawi Hilir, Tingkat Kecamatan, Tingkat Kota maupun Tingkat Provinsi sehingga kontribusi nyata kelompok Wanita Tani Arai Pinang mendukung PKK KB KES Desa Talawi Hilir memperoleh juara 1 kategori pelaksanaan Kegiatan Lingkungan Bersih dan Sehat Tingkat Provinsi.

e. Kelompok Wanita Tani Arai Pinang Lestari membuka ruang bagi pihak-pihak yang ingin belajar, studi banding ke kelompok Arai Pinang sebagai bentuk kontribusi kelompok dalam pengembangan pangan dan pemanfaatan pekarangan terutama dalam pembangunan Kota Sawahlunto.

f. Kelompok Arai Pinang mendapat kunjungan dan bimbingan

Dalam rangka Pengembangan Sumber

Daya Kelompok Wanita Tani Arai Pinang Lestari dilakukan berbagai hal, antara lain :

1. Pertemuan Kelompok, yang mana pada pertemuan kelompok penyuluh pertanian melakukan pembinaan terhadap kelompok, administrasi kelompok, pembinaan teknis mulai dari perencanaan pelaksanaan, evaluasi, dan monitoring terhadap kelompok.

2. Pertemuan rutin kelompok dalam bentuk gotong royong di bawah bimbingan penyuluh pertanian lapangan dalam pengelolaan kebun bibit dan kebun contoh sehingga dapat memberikan pembelajaran dalam budidaya, pemeliharaan tanaman, panen dan pasca panen.

3. Kunjungan atau anjang sana, yang mana penyuluh pertanian melakukan pembinaan terhadap anggota kelompok secara perorangan, hal ini dilakukan karena setiap anggota memiliki karekteristik yang berbeda dengan permasalahan yang beragam. Pemberian motivasi pelaksanaan, evaluasi dan monitoring keanggotaan secara langsung memberikan dampak yang positif kepada anggota, hal ini memberikan motivasi tersendiri bagi setiap anggota.

4. Demonstrasi, penyuluh pertanian secara proaktif memberikan demonstrasi terhadap berbagai teknologi pertanian yang ditransfer pada setiap kunjungan dan pertemuan yang dilakukan.

5. Kunjungan dan pertemuan yang dilakukan oleh tim penggerak PKK Desa, tim penggerak PKK Kecamatan, dan tim penggerak PKK Kota Sawahlunto yang mana anggota KWT mendapat bimbingan, motivasi dan pelatihan dalam pengolahan pangan local, pemanfaatan limbah, pengolahan sampah kering.

6. Pembinaan administrasi kelompok oleh UPTD-BPP Kecamatan Talawi

7. Pembinaan budidaya tanaman pekarangan oleh Dinas Pertanian dan Kehutanan Kota Sawahlunto sekaligus memberikan bimbingan dan motivasi untuk peningkatan ekonomi keluarga.

8. Melalui rumah pembibitan, anggota kelompok diajarkan tentang pengelolaan pembibitan berbagai jenis tanaman secara langsung oleh penyuluh pertanian, UPTD BPP Kecamatan Talawi dan Dinas Pertanian dan Kehutanan Kota Sawahlunto sehingga anggota mendapat pengetahuan dan keterampilan dalam pengelolaan pembibitan.

9. Melalui kegiatan Kawasan Rumah Pangan Lestari diberikan motivasi dalam pembibitan, pengolahan lahan, budidaya, pemeliharaan tanaman, panen, pasca panen dan pengolahan pangan lokal dalam rangka mengurangi konsumsi beras dan terigu. Hal ini akan memberikan semangat dan motivasi dalam pengelolaan pangan di pekarangan secara optimal.

Jadi jelaslah dengan adanya Program Kawasan Rumah Pangan Lestari ini berdampak baik sekali bagi kehidupan masyarakat terutama bagi Kelompok Wanita Tani Arai Pinang Lestari, yang mana pengetahuan dan wawasan anggota kelompok akan pentingnya gizi makin bertambah, pendapatan perekonomian keluarga juga meningkat. 
Kendala yang dihadapi dalam Implementasi Kebijakan Perpres Nomor 22 Tahun 2009 Dalam Memberdayakan Masyarakat Untuk Melaksanakan Program Kawasan Rumah Pangan Lestari.

Menurut Manurung (2003:38) Program akan diimplementasikan tidak lepas dari berbagai faktor yang turut memberikan pengaruh terhadap program itu sendiri. Kebijakan suatu Program dipengaruhi oleh beberapa faktor baik internal maupun faktor eksternal. Kendala yang dihadapi oleh Kelompok Wanita Tani Arai Pinang Lestari dalam pelaksanaan Program Kawasan Rumah Pangan Lestari antara lain adalah :

1. Faktor Internal adalah mencakup keseluruhan program yang dapat dikendalikan baik oleh pimpinan maupun oleh anggota organisasi yang bersangkutan. Adapun faktor internal yang mempengaruhi perkembangan kelompok untuk melaksanakan Program Kawasan Rumah Pangan Lestari adalah sebagai berikut

a. Kurangnya motivasi anggota dalam mengikuti kegiatan kelompok baik dalam hal pemahaman program, partisipasi dan kreatifitas yang dapat berpengaruh terhadap perkembangan dan kemajuan kelompok.

b. Kurangnya pengetahuan dan wawasan anggota kelompok untuk mengolah hasil pekarangan mereka untuk dijadikan sebagai olahan pangan lokal yang dapat dijual ke kantin-kantin sekolah sebagai jajanan anak sekolah.

2. Faktor Eksternal adalah faktor yang mempengaruhi diluar organisasi berupa lingkungan ataupun sosial budaya masyarakat. Faktor eksternal yang mempengaruhi adalah :

a. Kondisi cuaca yang ekstrim terkadang turut menurunkan semangat dan partisipasi anggota dalam pengelolaan usaha pemanfaatan pekarangan.

b. Masih kurangnya pedagang pengumpul untuk mengambil hasil-hasil pekarangan anggota yang sudah panen untuk dapat dijual.

Upaya Pemerintah Dalam Implementasi Kebijakan Perpres Nomor 22 Tahun 2009 Dalam Memberdayakan Masyarakat Untuk
Melaksanakan Program Kawasan Rumah Pangan Lestari.

Program Kawasan Rumah Pangan Lestari merupakan salah satu kebijakan pemerintah saat ini dalam rangka upaya mengurangi ketergantungan masyarakat terhadap salah satu jenis komoditi pangan pokok yaitu beras agar dapat lebih didiversifikasikan dengan komoditi pangan lainnya seperti umbi-umbian dan lebih banyak mengkonsumsi sayur-sayuran dan buah-buahan.Masyarakat juga diharapkan agar dapat mengurangi ketergantungan terhadap terigu yang jelas-jelas termasuk komoditi impor yang harganya semakin hari semakin meningkat. Upaya-upaya dalam implementasi kebijakan perpres nomor 22 tahun 2009 dalam memberdayakan masyarakat untuk melaksanakan Program Kawasan Rumah Pangan Lestari di Kelompok Wanita Tani Arai Pinang Lestari antara lain adalah :

1. Memberikan penyuluhan-penyuluhan dan sosialisasi dari dinas instansi terkait kepada anggota kelompok tentang pentingnya diversifikasi pangan bagi anggota keluarga.

2. Memberikan pengetahuan dan wawasan kepada anggota kelompok dari Dinas Kesehatan Kota Sawahlunto bagaimana menyajikan menu-menu yang lebih beragam, bergizi, seimbang dan aman yang akan dikonsumsi oleh anggota keluarga.

3. Memberikan pelatihan-pelatihan dari Politeknik Payakumbuh kepada anggota kelompok bagaimana mengolah hasil-hasil pekarangan mereka yang berasal dari komoditi umbi-umbian agar menjadi makanan olahan yang lebih menarik dan bergizi yang dapat disajikan dan dikonsumsi oleh anggota keluarga.

4. Memberikan dorongan semangat dan motivasi kepada anggota kelompok agar mereka lebih giat dan lebih aktif lagi dalam mengolah lahan pekarangannya sehingga menjadi lahan-lahan yang subur dan hijau yang dapat dijadikan sebagai seni keindahan yang ada di lahan pekarangan dan hasilnya pun dapat dijadikan sebagai sumber pangan keluarga yang lebih aman dari pestida dan racun-racun berbahaya yang dapat merusak kesehatan anggota keluarga.

5. Memberikan bimbingan dan saran-saran kepada anggota kelompok agar selalu menjaga kekompakan dan kerjasamanya 
sehingga suasana keakraban dan jalinan silaturrahmi terjaga dengan baik yang pada akhirnya kehidupan sosial dimasyarakat dapat lebih meningkat.

Memberikan bimbingan dan pelatihan dari penyuluh-penyuluh pertanian bagaimana menata dan mengolah lahan-lahan pekarangan, baik pada saat musim hujan maupun pada musim kemarau sehingga hasil pekarangan dapat menghasilkan panen yang bagus yang dapat dijadikan sebagai sumber pangan keluarga yang sehat dan bergizi.

\section{CONCLUSION}

1. Implementasi Kebijakan Perpres Nomor 22 Tahun 2009 Dalam Memberdayakan Masyarakat Untuk Melaksanakan Program Kawasan Rumah angan Lestari merupakan salah satu upaya untuk memberikan wawasan dan pengetahuan kepada anggota Kelompok WanitaTani Arai Pinang Lestari agar lebih mengurangi ketergantungan terhadap komoditi beras.

2. Pengetahuan masyarakat terutama kelompok Wanita Tani Arai Pinang Lestari bahwa perlunya diversifikasi pangan dalam menyajikan menu-menu yang akan dikonsumsi oleha nggota keluarga lebih meningkat sehingga mereka dapat mengkonsumsi makanan yang lebihberagam, bergizi, seimbang dan aman dalam rangka perbaikan kualitas sumberdaya manusia bagi generasi dimasa mendatang.

3. Kondisi lahan yang semakin hari semakin terbatas, membuat Kelompok Wanita Tani Arai Pinang Lestari lebihmengoptimalkanlahan-lahan pekarangan mereka agar tidak terlantar begitu saja tetapi menjadi lahan-lahan yang produktif dan potensial yang dapat dijadikan sebagai sumber pangan keluarga bahkan dapat dijadikan sebagai sumber pendapatan keluarga.

4. Hasil-hasil komoditi pekarangan berupa komoditi umbi-umbian seperti ubi kayu. Ubi jalar, jagung, pisang dan komoditi sukun dapat dijadikan sebagai tepung yang dapat diolah menjadi makanan-makanan olahan yang menarik dan bergizi sekaligus dapat

digunakan untuk pengganti terigu yang pada akhirnya ketergantungan masyarakat terhadap komoditi impor seperti terigu dapat dikurangi.

1. Kepada anggota Kelompok Wanita Tani Arai Pinang Lestari diharapkan untuk lebih aktif dan lebih berpartisipasi alam optimalisasi pemanfaatan pekarangansehingga upaya diversifikasi pangan dalam rangka Implementasi Kebijakan Perpres Nomor 22 Tahun 2009 untuk melaksanakan Program Kawasan Rumah Pangan Lestari dapatterus berjalan dan bermanfaat bagi kelompok.

2. Laksanakan pertemuan kelompok secara rutin dan teratur agar kekompakan dan kerjasama anggota tetap terjaga dan terpelihara dengan baik dan kehidupan sosial di masyarakat dapat lebih meningkat.

3. Diharapkan terjadinya perubahan perilaku dan kebiasaan pola konsumsi bagi anggota Kelompok Wanita Tani Arai Pinang Lestari yang lebih mengarah kepada konsumsi pangan yang lebih beragam, bergizi, seimbang dan aman yang akan disajikan sebagai menu keluarga menuju pembangunan sumber daya manusia yang lebih berkualitas dimasa yang akan datang.

Kepada anggota kelompok diharapkan agar mengurangi ketergantungan terhadap konsumsi beras dengan mengganti dengan komoditi umbiumbian dan memperbanyak mengkonsumsi sayur dan buah-buahan sehingga upaya yang diharapkan pemerintahuntuk menurunkan konsumsi beras 1,5\% per tahun dapat tercapai. 


\section{Bibliography}

Kusnadi, 1996, Pembangunan Masyarakat Pedesaan. Jakarta: Gramedia Pustaka Utama.

Manurung 2003, Teori dan Konsep Pembangunan Ekonomi. Jakarta: Gramedia Pustakaindo.

Nugroho, Rian D. 2004, Pemberdayaan Masyarakat. Jakarta: Elex Media Komputerindo.

Pasolong, Harbani, 2002. Metode Penelitian Administrasi. Makasar: Lephas Unhas.

Suggono, Bambang. 1994. Hukum dan kebijakan Publik. Jakarta: Sinar Grafika.

Suharto, Edi 2006. Membangun Masyarakat Memberdayakan Rakyat. Bandung: PT Refika Aditama.

Sutrisno, 2005 .Strategi Pemberdayaan Masyarakat. Bandung: Humaniora Utama Press.

Sudjana, Nana. 2001. Penelitian Pendidikan. Bandung: Sinar BaruAlgesio.

Singarimbun, 1995.Metode Penelitian Survei. Jakarta:LP3ES.
Tjandraningsih,1996.

Desentralisasi Pemerintahan Dalam Pelaksanaan Pemberdayaan Masyarakat Terpadu. Jakarta:Bappenas.

Tampubolon, David, 2006. Pemberdayaan, Pengembangan Masyarakat dan Intervensi Komunitas. Jakarta: LembagaP enelitian FE-UI.

Usman, Husain dan Purnomo Setiady Akbar, 2011.Metodologi Penelitian Sosial. Jakarta: Bumi Aksara.

Wrihatnolo, Wismuadji, 2007 Manajemen Keuangan Untuk Usaha Kecil. Yogyakarta: Andi.

Wahab, Solichin Abdul, 2005. Analisis Kebijaksanaan. Jakarta: Bumi Aksara

Winarno, Budi. 2002. Kebijakan dan Proses Kebijakan Publik. Yogyakarta: Media Pressindo

Wursanto, Ig, 2005. Dasar-Dasar Ilmu Organisasi. Yogyakarta: Andi 